\title{
The Quality of Systematic Review Articles in the International Journal of Medical Reviews (IJMR)
}

\author{
Mohsen Saberi Isfeedvajani ${ }^{1}$ \\ ${ }^{1}$ Medicine, Quran and Hadith Research Center and Department of Community Medicine, Faculty of Medicine, Baqiyatallah \\ University of Medical Sciences, Tehran, Iran
}

Corresponding Author: Mohsen Saberi Isfeedvajani, MD, Associate Professor, Medicine, Quran and Hadith Research Center and Department of Community Medicine, Faculty of Medicine, Baqiyatallah University of Medical Sciences, Tehran, Iran. Tel: +982181263617, Email: drsaberihaji@gmail.com

Received March 4, 2017; Accepted March 20, 2017; Online Published March 28, 2017

\section{Dear Editor,}

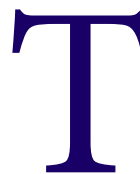

he preferred reporting system of systematic review articles is PRISMA statement. ${ }^{1,2}$ While reviewing the archive of the IJMR in the journal's website, and as reading the systematic review articles published in volume 3 , issue 3 and 2 of 2016, I found out that there was no reference to the PRISMA statement at all. ${ }^{3-10}$ Although, several studies have reported the lack of compliance with PRISMA. ${ }^{11-14}$ It is expected that in the near future the IJMR publishes systematic review articles that follow the PRISMA checklist.

The following suggestions can lead to increased compliance with the PRISMA checklist. The first step is

\section{References}

1. Moher D, Liberati A, Tetzlaff J, Altman DG, Group P. Preferred reporting items for systematic reviews and metaanalyses: the PRISMA statement. BMJ. 2009;339:b2535. doi: 10.1136/bmj.b2535. pmid: 19622551.

2. Moher D, Liberati A, Tetzlaff J, Altman DG, Group P. Preferred reporting items for systematic reviews and metaanalyses: the PRISMA statement. Int J Surg. 2010;8(5):33641. doi: 10.1016/j.ijsu.2010.02.007. pmid: 20171303.

3. Torabipour A, Qolipour M, Qolipour K. Medical tourism services quality analysis: a systematic review. Int J Med Rev. 2017;3(2):449-57.

4. Shahsavarani AM, Esmatnia M, Fayazi M, Kalkhoran $M H_{\text {, }}$ Shahcheraghi F, Sattari K. Systematic review of literature on stress assessment and evaluation: Methods, instruments, and applications in current biopsychosocial sciences. Int J Med Rev. 2017;3(2):407-21

5. Sardari M, Pazokian M. Relationship between Type 2 Diabetes and Depression: A Systematic Review. Int J Med Rev. 2017;3(2):423-8.

6. Rad RR, Pazokian M. Graves' Disease in Pregnancy: A Systematic Review. Int J Med Rev. 2017;3(3):489-93.

7. Mortazavi H, Shahsavari N. Early Tooth Loss Related to Medical Syndromes: Review of More Than 20 Entities. Int J Med Rev. 2017;3(2):429-37. to inform the authors of the articles in the author's guideline section of the IJMR website. The second step is to inform the reviewers of systematic articles to check this issue. Albeit, it is highly recommended that the editorial team i.e. editor-in-chief or assistant editor check this issue before sending article to reviewers. Although this process is time-consuming and difficult, over time, the quality of articles will definitely increase.

\section{Conflict of Interest Disclosures}

Author declares that he has no conflict of interest.

\section{Funding}

None.

8. Mohammadi E, Nasseri E, Ahari GK. Functions and Health Benefits of Conjugated Linoleic Acid: A Review of Controlled Clinical Trials. Int J Med Rev. 2017;3(2):439-46.

9. Mehrabi-Tavana A, Mehdizadeh P. Health Policies for Reducing Air Pollution in Iran. Int J Med Rev. 2017;3(2):45966.

10. Babu PC, Pachava S. Dental Outreach Programmes-A Path to Develop Service Motive. Int J Med Rev. 2017;3(2):447-51.

11. Simons $M$, Busch $K$, Avolio A, Kiat $H$, Davidson A Improving the quality of the evidence - The necessity to lead by example. J Clin Neurosci. 2017;46:165-6. doi: 10.1016/j.jocn.2017.09.004. pmid: 28974392.

12. Cullis PS, Gudlaugsdottir K, Andrews J. A systematic review of the quality of conduct and reporting of systematic reviews and meta-analyses in paediatric surgery. PLoS One. 2017;12(4):e0175213. doi: 10.1371/journal.pone.0175213. pmid: 28384296.

13. Kazerani M, Davoudian A, Zayeri F, Soori H. Assessing abstracts of Iranian systematic reviews and metaanalysis indexed in WOS and Scopus using PRISMA. Med J Islam Repub Iran. 2017;31:18. doi: 10.18869/mjiri.31.18. pmid: 28955668.

14. Nissen T, Wayant C, Wahlstrom A, Sinnett P, Fugate C, Herrington J, et al. Methodological quality, completeness of

Copyright $(\subset 2017$ The Author(s). This is an open-access article distributed under the terms of the Creative Commons Attribution License (http://creativecommons.org/licenses/by/4.0), which permits unrestricted use, distribution, and reproduction in any medium, provided the original work is properly cited. 
reporting and use of systematic reviews as evidence in clinical practice guidelines for paediatric overweight and obesity. Clin Obes. 2017:7(1):34-45.

doi:

Citation: Saberi Isfeedvajani M. The quality of systematic review articles in the International Journal of Medical Reviews (IJMR). Int J Med Rev. 2017;4(1):37-38. doi: 10.29252/ijmr-040107. 